Co-creation of information leaflets to meet the support needs of people living with Complex Regional Pain Syndrome (CRPS) through innovative use of wiki technology

K Rodham ${ }^{1 *}$, J Gavin ${ }^{2}$, N Coulson ${ }^{3}$ and L Watts ${ }^{2}$

${ }^{1}$ Staffordshire University, UK

${ }^{2}$ University of Bath

${ }^{3}$ Division of Rehabilitation and Ageing, University of Nottingham, Nottingham, UK

*Corresponding author:

Prof Karen Rodham,

School of Psychology, Sport and Exercise,

Staffordshire University,

Science Centre,

Leek Road,

Stoke-on-Trent

ST4 2DF

Email: karen.rodham@staffs.ac.uk

Tel: 01782294601

Competing interests: none declared

Key words: wiki, CRPS, information, support

Running head: Co-creating information leaflets with people living with CRPS using wiki technology 


\title{
Co-creation of information leaflets to meet the support needs of people living with Complex Regional Pain Syndrome (CRPS) through innovative use of wiki technology
}

\author{
Abstract \\ Objective: People living with Complex Regional Pain Syndrome (CRPS) experience frustration \\ with the lack of knowledge and understanding of CRPS as a pain condition. We report on our \\ attempt to address this issue.
}

Method: People living with CRPS taking part in a larger study were invited to co-construct a CRPS wiki page that addressed the areas in which they had experienced the most difficulty. A blank wiki page was set up for participants to populate with issues they felt needed to be raised and addressed.

Results: Participants failed to engage with the wiki technology. We modified our procedure and completed an inductive analysis of a sister-forum which participants were using as part of the larger study. Six issues of importance were identified. We used the discussion forum threads to populate the themes. Due to a continued lack of engagement with the wiki technology, the team decided to create a suite of leaflets which were piloted with delegates at a CRPS patient conference.

Conclusions: Future work should be mindful of the extent to which patients are able and willing to share their experiences through such technology. Striking the balance between patient-endorsed and researcher-driven co-creation of such material is imperative. 
Development of information leaflets to meet the support needs of people living with Complex Regional Pain Syndrome (CRPS) through innovative use of wiki technology

Complex Regional Pain Syndrome (CRPS) is difficult to diagnose and is characterised by burning pain in one or more limbs, swelling, temperature and colour changes, with $15-20 \%$ of patients developing long-term disability [1]. It has an incidence of 5.46-26.2 per 100,000 person years [2], the cause is unknown and there is currently no cure. For those patients whose symptoms do not spontaneously resolve within the first year, long-term residual symptoms or impairment are common. Treatment is palliative rather than curative and so focuses on improving function.

The impact on, and needs of, people living with CRPS are beginning to be documented in the research literature (e.g.3-7). It is clear that CRPS can have a negative impact on the physical, emotional, social and financial aspects of patients' lives [8]. CRPS pain is often invisible and is difficult to explain to family, friends and colleagues. In addition, patients are faced with the frustration of no longer being able to do the things they used to and can lose their sense of identity. Furthermore, patients have reported that their health professionals lacked knowledge of CRPS and this was a source of considerable frustration [5, 7]. Similarly, a study on the carer experience of CRPS demonstrated that carers were disappointed to discover that CRPS was not well known or understood by health professionals [4].

This lack of knowledge and understanding causes considerable distress for people living with CRPS. For example, participants in Rodham et al's (2012:p1157) [6] study mentioned the lack 
of CRPS expertise amongst the health profession. The participant Justine said: "But they actually don't know the condition. And that to me is really worrying". The lack of CRPSawareness on the part of the health profession, impacts on the person with CRPS in myriad ways. Without support and understanding from the health profession, it is difficult for people with CRPS themselves to understand their condition, and this in turn impacts on their ability to explain their condition to friends, family, employers and other health professionals involved in their care.

Researchers focusing on chronic conditions have noticed that whilst providers of healthcare usually define problems in terms of poor compliance or continuation of unhealthy behaviours, patients are more likely to define problems in terms of pain, symptoms and interference with their ability to carry out their everyday activities. This difference in focus and in perception is important because without a shared view of a condition, collaborative working between health professionals and patients will be impossible. Indeed, Von Korff, Gruman, Schaefer et al (1997) [9] note that in order for health practitioners and patients to collaboratively manage a condition, they need first to define problems clearly.

For people living with CRPS the desire and need for information is of paramount importance and they commonly turn to the Internet to search for CRPS-related information. The Internet is a resource that is increasingly used where health issues and peer support are concerned [10], whether in the form of web pages of official health organisations or charities, informal groups, individual blogs, vlogs, or the pooled discussions of experiences in online forums. Whilst there is much scope for the proliferation of misinformation and 'scare-stories' [11], 
equally, there is opportunity for people who have to cope with a rare and personally challenging condition to discover that they are not alone. The internet can give everyone a voice and so it is possible to read authentic first-hand experiences of others who are or who have encountered the trials an individual now faces. Participants in the Rodham et al study [7] talked candidly about their search and desire to find the 'right' kind of information, and although the Internet was considered an untrustworthy place, at the same time it was the resource that was most available to them. If people with the condition are anxious, frightened and misinformed after searching online, it is likely that other groups, such as friends, family and employers may share similar concerns. There is therefore a need for trustworthy and balanced information that contains common (not worst-case) experiences of people who are themselves living with CRPS.

One way to address this gap in information and awareness is to involve people living with CRPS explicitly in the co-creation of information resources that directly address the areas in which they have experienced the most difficulty. Indeed, patient involvement has been described as an 'essential though clearly overlooked component in the development of information resources' [12:p13]. Van de Belt and colleagues [13] suggest that failure to involve patients in the development of patient-information is a 'missed opportunity' and Kennedy [14] notes that since both health professionals and patients are experts in their own fields, the one in clinical matters, the other in his or her experience and feelings, both should be involved in the development of information resources. One obvious and potentially useful tool through which to involve this group is via the Internet. Indeed, with the rise of the Internet and social media, many people are familiar and comfortable with 
using technologies such as email, Facebook and online forums. For those with a disabling and painful condition such as CRPS, the online environment offers a means of contributing to, and accessing information that would otherwise be unavailable to them [e.g. 15]. A further benefit of co-creating information resources is that the process involves written rather than oral communication; actively writing about one's experiences has been shown to be beneficial in terms of emotional well-being [16-20], reductions in self-reported symptoms [21] and improvements in mood [17]. In addition, Archambault and colleagues (2013) [22] argue that involving patients in the creation and dissemination of knowledge in fact empowers them to apply their knowledge in practice. However, the research that has involved both patients and health professionals has had mixed results. Information resources were created, but the amount of active patient involvement compared to that of health professionals was low [e.g. 22]. Furthermore, many of the studies completed to date have focused on the benefits for health professionals and students, rather than for patients [22]. With this in mind, we explored whether using wiki technology could meet the support and information needs of people living with CRPS.

A wiki is essentially a collaborative writing application which allows anyone with access to create, add to and alter online content [22]. In this paper, we report on the development of a co-created information resource explaining CRPS from our participants' 'patientperspective'. The intention was to create a companion wiki page that would complement an existing CRPS wiki page [23] created by professionals but lacking the patients' voice, experience and perception of CRPS. Such an information resource would be useful for both people living with CRPS and health professionals who are not likely in the course of their 
career to encounter many people living with CRPS [24]. Therefore the opportunity to understand CRPS from the perspective of the person living with the condition will be invaluable in enhancing the ability of health professionals to support and normalise the experiences of those patients they do encounter.

\section{Method}

Participants were invited to take part in a collaborative writing task to co-construct a web page presenting CRPS, addressing misconceptions and ensuring that the point of view of people with CRPS themselves was represented.

Participants: Participants for the writing task were drawn from those who were already members of a forum we had set up as part of a larger project. This larger project had two objectives; the first to explore how support develops when users join a newly launched online forum. The second aim was to create an opportunity for people with CRPS to develop a CRPS wiki information resource (a writing task) that encapsulated and represented their voice. In this report, we focus on the second aim of the larger project.

The forum for the larger project had been running for six months. There were 62 forum members, 29 threads, and 217 topics on the forum. All 62 participants in the larger study were invited to contribute to the proposed wiki-information resource. The 'wiki', a Hawaiian word meaning 'quick', is a type of interactive technology that was created to allow groups of people with common interests to write about them collectively. Although the concept of the wiki is now entwined in public consciousness with the online encyclopedia 'Wikipedia', wikis 
are in use by many groups and organisations, often as member-generated repositories of knowledge [25]. The central facet of a wiki is collective authorship; the wiki should support multiple authors contributing and editing the same content. Wikis use a simplified markup language both to make them accessible to non-technical users and to minimize the effort of participation. If viewed as static web pages, they appear very different from internet forums and are akin to any other fixed written resource. However, wikis are by design conversational technologies that encourage joint ownership though authorship, subject to power differences in community membership [26]. They are contended spaces, subject to dispute and collective debate, which reinforces engagement in mutual support and coordination around the content produced by community members [27].

The intention was to artificially create as near a proxy for a naturalistic study of a newly formed community-driven online forum for people with a psychologically challenging health condition, emphasizing collective exchange of experience. Outside of our research site, it is possible for anyone who cares about an issue to contribute to a corresponding page on Wikipedia; likewise, we wanted to ensure that anyone who was participating in our forum could participate in the development of the wiki.

The anonymous nature of the Internet means that demographic information about participants was limited. As in real life online environments (no longer an oxymoron), in our forum it was impossible to know any more about participants (community members) than that which they were prepared to disclose themselves. However, examination of the selfdisclosed content of postings made it possible to obtain some information about 26 of the 
62 members: Seven were males (26.9\%) and 19 females (73.1\%). Age was available for 9 participants, ranging from 20 to 54 years with a mean age of 35.6 years. This is similar to the reported prevalence of CRPS in the wider population, which typically affects more females (a ratio of 4 females to 1 male) in their forties. [2] Self-reported number of years since diagnosis was available for 14 participants, ranging from 5 months to 10 years with a mean duration of 3.9 years (we were mindful that the difficulty involved in diagnosing CRPS means that some participants will have experienced symptoms for quite some time before being formally diagnosed).

To understand more about our sample, we created a special thread in the forum called 'Your chance to tell us a bit about yourself', with a posting by a researcher which read: "If you are new here (just registered with the forum), please introduce yourself in this section. Write as much or as little as you like."

There were 75 further posts in this thread by 20 unique members, each of whom responded to the researcher's initial post by writing some autobiographical information. In total, this thread includes approximately 12000 words of descriptive prose, setting out matters each member felt relevant as they presented themselves to fellow forum members. Whilst this information is certainly not uniform or controlled, it represents an authentic voice of the experiences of people who are living with CRPS. The information disclosed was clearly at the discretion of the member concerned and so is likely to have been partial and selective. However, it provides a valuable window onto the experiential nature of the condition, and with the quality of engagement other members of this online health community. Consider 
the following post as an exemplar of the physical, psychological and social concerns such introductions raise (emphasis added, XXXX used to anonymize):

"Hello! Am not sure if I am writing this in the right place - but here goes! I have CRPS in my left arm following a broken humerus in January 2011. It extends from my left shoulder to fingertips - and yes, I am left handed! I was lucky to be diagnosed relatively early - after 6 months - thanks to my hydrotherapist at the XXXX. I was really grateful for this - as other people were telling me that I wasn't trying hard enough etc, even though I couldn't move my arm, shoulder and hand...! I also tried to keep my fingers moving as much as possible right from the beginning - my arm and hand were really swollen and I was worried it would all seize up. I play the piano so kept doing exercises with my hand - I'm sure this helped a lot. However - I can't play properly - but can busk along happily! I have kept my good sense of humour - and always try to keep positive; I am still me - just with a painful dysfunctional arm! I feel sure that being left handed - and instinctively wanting to use it, and keeping my dexterity playing 'air piano' has helped a lot. One of my biggest frustrations is not being able to work - having had to leave my job because I had lost the dexterity to do the work - and not as yet being able to find a job I can sustain. If anyone out there knows of any 'Home-working' opportunities that are reliable - I would love to know! I am trying to get back into basic music teaching and learning support - I miss the social interaction, as well as the income! So - if anyone needs a wonky-armed piano player, whose left hand boogie-woogie has seen better days, please give me a shout!" Other postings were typically encouraging, emphatic and welcoming. For example, a response to this post was: 
"Hi XXXX, and welcome, Im your other half lol!! Mine is in my right hand up to my shoulder and yep Im right handed too. Wow how lucky were you to be diagnosed that quick. Im not a piano player, but many many years ago I could play the bagpipes, and thats something, as Ive no ties to Scotland, and Im a born and bred Londoner.

$$
\text { :) :) " }
$$

Ethical considerations: The CRPS support group from whom participants were recruited was independent of the National Health Service (NHS). As a consequence, the Chair of the local NHS Ethics committee confirmed that the study did not require NHS ethics approval. The project received approval from the University Ethics committee. Consent was sought from all participants prior to taking part. They were informed that they could withdraw at any time, but that their data up until the point of withdrawal would be kept and analysed by the researchers. All names used and mentioned on the site were anonymised by the research team, prior to analysis.

Planned Procedure: The CRPS Web forum used in the larger study was only open to research participants and was password-protected. Individuals were required to agree to the rules of the forum to join the project and register with a username and password before they could access the forum and view messages posted by other individuals. All members were informed during the registration procedure that the forum was part of a research project and they gave full informed consent to their forum postings being used anonymously for research purposes. The welcome page reminded members of the forum etiquette, the fact that it was a research project and that the space was theirs to make of what they would. The 
discussion forum was divided into three distinct message boards: 'Welcome', 'Your thoughts and experiences', and 'Is the forum working for you?'. The latter was a space for participants to report any problems they were having with the forum. The collaborative writing task was linked to the forum, but was situated in a separate wiki page that we had intended participants would populate by building the content themselves. After the forum had been running for six months, members were invited to develop the proposed wiki page. The invitation is reproduced in Box 1 below. Members were also directed to a link which explained simply how to use the wiki.

\section{BOX 1 ABOUT HERE}

\section{Results}

Our participants did not engage with the wiki page; after two weeks only two people had actively engaged and made lengthy contributions detailing their thoughts about what should be included, but this did not stimulate discussion as we anticipated. Our original plan had been to facilitate the creation of the wiki by providing the platform (see Figure 1). We wanted to learn how members decided on the topics and information that they considered important. The beauty of wiki technology is that there is a record of the discussions and of how they were resolved. Since the members did not engage with this, we were forced to modify our procedure.

\section{FIG 1 ABOUT HERE}

Modified Procedure: To address the lack of response from participants, we consulted the research Steering Group, who recommended that we approach those members for whom 
we had email details and invite them to contribute their thoughts anonymously via the research team. We also completed an inductive thematic analysis [28] of the posts on the 'Welcome' and the 'Your thoughts and experiences' forum pages to identify key themes that had repeatedly been discussed. We combined these with the suggestions from the two participants who had posted their thoughts, as well as the responses from the participants who had emailed the team and identified six key themes (friends \& family, employers, health professionals, benefits agencies, links to other resources, what is CRPS?). We posted this information in a new forum sub-board entitled 'Raise awareness of CRPS', which contained threads corresponding to the six themes. This approach created a safer start-point, and discussion subsequently picked up a little. However, participants did not engage with the task via the wiki itself, instead preferring to email the research team with their comments and instructions for adding to, or changing the content of the draft wiki, rather than make amendments themselves. This meant that as a research team we had a skeleton outline for the wiki page, but participants were reluctant to play an active role in contributing to it. Given the lack of engagement with the online wiki resource, the team reasoned that although it would be possible to create a wiki page using the information gathered, if participants were not engaging with the technology in a study they had actively wanted to be a part of, it would be unlikely that the wider CRPS community would engage with and further develop this resource. Instead, the decision was taken to use the information to create a suite of leaflets targeted at key groups participants had mentioned. The draft leaflets were presented at a patient-led conference, and the delegates invited to provide feedback. Sixteen out of fifty delegates responded with written comments. These comments 
were incorporated into the final leaflets. (See Figure 2). The results of the modified procedure are reported below.

\section{FIGURE 2 ABOUT HERE}

\section{Results of the modified procedure}

As mentioned above, six key themes were identified as being of importance to people living with CRPS. Each is detailed below:

CRPS Symptoms and progression: Participants had spoken often and openly on the forum about the many and varied signs and symptoms of CRPS. On the basis of these forum discussions, the team was able to describe the symptoms of CRPS as experienced by those living with CRPS. Participants had a strong desire to ensure that everyone's symptoms had been captured in their entirety. However, to include all possible symptoms would have resulted in an overwhelmingly large section of the proposed wiki page, and it would have run counter to the original idea that was to ensure that simple, clear and accessible information about CRPS and about the experience of people living with CRPS was shared. There was tension between wanting one's own symptoms validated by inclusion in the information resource and getting a clear and simple message across that would better inform targeted groups about CRPS. Other issues covered in this section included 'what CRPS is not'; a resource countering and addressing the myths and misunderstandings participants had encountered. Finally, attention was also paid to explaining how CRPS can impact on a person with CRPS. This was a key element that participants felt was missing from the wiki page that had been written by professionals. 
Friends \& family: Forum discussions demonstrated an awareness that CRPS also impacted on participants' friends and family. There was also recognition that it was difficult for friends and family to fully understand CRPS and that as a consequence friends and family often absented themselves from the life of the person with CRPS. Mention was made in the forum of lost friendships and broken marriages. What forum members felt was needed was information to explain to friends and family what CRPS was, how it impacted on the person with CRPS, and more importantly, how the friends/family could best help the person with CRPS to cope. This is what guided our development of this section.

Health professionals: Participants' frustration at encountering health professionals who lacked understanding of CRPS was clearly evidenced in the forum discussions. First, members wrote about the profound impact on them of encountering an uninformed health professional. Linked to the lack of knowledge was the inappropriate and insensitive behaviour they had encountered; participants wrote about uninformed health professionals touching or moving their affected $\operatorname{limb}(\mathrm{s})$ without understanding why this was inappropriate. They also felt that health professionals did not actively listen to them.

Employers: Participants were clear that employers needed to be made aware that CRPS could become a life-long condition that needed special consideration and adaptation in the context of the workplace. They were keen to emphasise that it was possible to work with CRPS provided employers made reasonable adaptations within the workplace setting. Suggestions for what these might be were shared. The key message was that "employers' need to know that it is a genuine condition and the associated disability needs support" 
Benefits agencies: There was a strong desire for benefits agencies to be better informed. Some participants felt that benefits agencies a) did not understand CRPS and b) as a consequence, failed to offer appropriate support. However, since participants did not actively contribute to expanding this section, it remained sparse in content and was not included in the final information resources.

Links to other resources: In the forum discussion, members shared news articles and web resources (usually US-based). The research team contributed to this section by adding UKbased resources such as the Royal College of Physicians CRPS guidelines [29].

Having created content for five of the six themes (benefits agencies was dropped due to lack of information), the team created three draft leaflets; one directed at health professionals, one at friends and family, and the third at employers. Each leaflet contained information about what CRPS was and had links to other resources.

\section{Piloting the leaflets}

Although the leaflets were in-effect co-created, the co-creation process had not been as interactive as the team had planned. We were mindful that the key reason for engaging in this aspect of the research was to address the patient-identified gap in existing information resources; namely the lack of the patient-voice. However, since the patients had been reluctant to engage with the process, we had to access their voice via online forum discussions. In order to check that the patient voice was fairly represented, the draft leaflets 
were piloted at a patient-run conference on October 12th 2013. Fifty patients attended the conference, all of whom received copies of the draft leaflets and a feedback sheet. Sixteen provided detailed written feedback, all of which was overwhelmingly positive and constructive (see Table 1). We incorporated the suggestions made for improving the leaflets (which are now available online [30]).

TABLE 1 ABOUT HERE

Table 1: Participant comments on the draft leaflets

\section{Discussion and Conclusions}

The research was developed to address an expressed need from a group of people living with CRPS who felt that their voice and experience was missing from much of the information they had been able to access. We invited people living with CRPS to participate in a collaborative writing task to develop a wiki page that would provide them with a platform to share and give voice to their experiences of living with CRPS. As researchers, we set out to understand how active engagement in collaborative writing could reflect and support the positive sharing of experiences about a psychologically challenging health condition. We elected to use a wiki platform to do this but believed that the health community we focused on would benefit from a 'forum phase' first, to establish themselves as an online group in a more familiar mode of communication. The technical basis of the project was a wiki platform known as 'mediawiki', the same platform used by Wikipedia. We created a forum on this platform and found our CRPS community were engaging with it, 
sharing a variety of thoughts, ideas, advice and empathic sentiments. However, when we exposed its wiki functionality to the community, we discovered that it did not engage them.

Although we failed to achieve the original aim of the study, by adapting our planned procedure, we were able to co-create a suite of CRPS information resources that incorporated the voice and experiences of people who were themselves living with CRPS. In summary, although our original idea to develop a sister wiki page for the existing health professional oriented page was not realised, we did produce a co-created information resource that was enthusiastically endorsed by people living with CRPS. Thus, whilst the content of the leaflets was drawn from the posts on our forum and from email correspondence, this content has been endorsed by a wider group of people living with CRPS - those who attended the patient conference. We are therefore confident that the content is such that it reflects the views and experiences of the wider CRPS population, and not just those who took part in our forum.

Of particular importance is the finding that our participants did not embrace the planned procedure. Although the modified procedure worked better, participants remained reluctant to engage with the shared development of the online wiki resource. Others have recently reported their experiences of developing information leaflets for people with fertility problems using wiki technology [13]. They suggested that wikis were an excellent example of a collaborative writing application because they enabled online documents to be edited collectively. Whilst this is indeed an advantage of the wiki technology, we found that our participants did not embrace this opportunity; there was hesitancy about openly stating 
their ideas or preferences for what material should/should not be included in the online resource. Participants preferred instead to allow the research team to take the lead; this is similar to the experience detailed by van de Belt et al. (2014) [13] who found that health professionals were more proactive in their contributions, whilst patients in their study were only responsible for between $13-17 \%$ of revisions. This means that the patients' voice in the output(s) from that study is likely to be under-represented. The lack of participant engagement with wiki tools reported by ourselves and others [e.g. 13] might be a reflection of the different experiences of these two groups; professionals are perhaps more used to sharing ideas openly and receiving criticism (constructive or otherwise) and are perhaps more resilient and so less anxious about doing so. Patients on the other hand, are perhaps used to sharing ideas and thoughts in the online setting with peers in less formal and more ephemeral manner such as on Facebook, where comments and conversations soon slip down the screen as they are replaced by more recent interactions. We suggest that when asked to share experiences and opinions in the context of the development of a 'formal' resource that patients feel inhibited or fearful of judgement or concerned that their own unique experience is taken as the common experience. As health professionals and academic researchers we need to be more proactive in addressing the power imbalance that exists when working with participants so as to ensure they are comfortable expressing their opinions and experiences.

It is possible that the mode of interaction between the members of our CRPS community was thoroughly embedded in the turn-taking model that is supported by the structure of an online forum. Although wikis are conversational in nature, in that they support an exchange of views around collaboratively authored information, such discussions tend not to be 
chronologically ordered but organised around the order of concepts in the article. This is structurally at odds with the organisation of a forum, where conversational threads are created in successively incremented in time with contributions from forum members. More research is required on how to support people in combining forum- and wiki-structured conversational exchanges, as they explore and express viewpoints on their experiences of health conditions.

Despite these difficulties, our study benefited from the use of $360^{\circ}$ feedback, in that the online interactions between people with CRPS led to the development of the leaflets, which were then piloted with another group of people living with CRPS. We are confident that we have ensured that the patient voice and concerns have been captured and are clearly represented in the finished leaflets. The content and presentation of the finished leaflets is very much a reflection of co-creation between people living with CRPS and the researchers.

\section{Implications and Future Research}

Future research may usefully explore the conditions under which patients feel able and willing to actively contribute to online or printed information resources. Particular attention should be paid to exploring what support researchers and health professionals can put in place to encourage more patients living with conditions, such as CRPS, to share their experiences, as well as consideration as to how best to share this information with both health professionals and other patients.

\section{Conclusion}


Patients living with CRPS welcomed the opportunity to have their voices heard and to cocreate information leaflets targeting various groups though not through the process originally planned by the research team. Similar endeavours in this and other patient groups should be mindful of the sensitivities and barriers that may limit the extent to which patients are able and willing to share their experiences through such technology. Striking the balance between patient endorsed and researcher-driven co-creation of such material is imperative.

\section{Acknowledgements}

We thank the National Institute of Health Research Health Services Research Programme for funding our study (Ref 10/2000/40). We also thank our research participants who contributed to the writing of the leaflets. We would also like to thank Sharon Grieve, and our technical officer Martin Post for their advice and support. We are particularly grateful to Julie Weymouth for her invaluable help in recruitment, and for her advice as expert-patient. Finally, we would like to thank Hannah Heath, our Research Assistant. 


\section{References}

[1] Geertzen JHB, Dijkstra PU, van-Sonderon EL, Goothoff JW, ten Duis HJ, Elsma, WH. Relationship between impairment, disability and handicap in reflex sympathetic dystrophy patients: a long-term follow-up study. Clin Rehabil 1998; 22: 402-412.

[2] Sandroni P, Benrud-Larson LM, McClelland RL, Low PA. Complex regional pain syndrome type I: incidence and prevalence in Olmsted County, a population-based study. Pain 2003; 103: 199-207.

[3] Kelmer M, Furnée CA. The impact of chronic pain on life in the household. J Pain Symptom Manag 2002; 23: 433-441.

[4] Lauder A, McCabe C, Rodham K, Norris E. An exploration of the support person's perceptions and experiences of complex regional pain syndrome and the rehabilitation process. Musculo Care 2011; 9: 169-179

[5] Rodham K, McCabe C, Blake D. Seeking support: An Interpretative Phenomenological Analysis of an Internet message board for people with complex regional pain syndrome. Psychol Health 2009; 24: 619-634.

[6] Rodham K., Boxell E., McCabe C., Cockburn M. Waller E. Transitioning from a hospital rehabilitation programme to home: Exploring the experiences of people with Complex Regional Pain Syndrome, Psychol Health, 2012; 27(10), 1150-1165.

[7] Rodham K, McCabe C, Pilkington M, Regan, L. Coping with chronic complex regional pain syndrome: advice from patients for patients. Chronic Illness 2013; 9: 29-42.

[8] Rodham K. Learning to Cope with CRPS / RSD: Putting life first and pain second. Singing Dragon: London, 2014 (in press) ISBN: 978-1-84819-240-9 
[9] Von Korff, M., Gruman, J., Schaefer, J., Curry, S.J. \& Wagner, E.H. Collaborative management of chronic illness. Ann intern Med 1997;127, 1097-1102.

[10] Coulson, N.S. \& Malik, S. Health-related online support communities. In Z. Yan (Ed.). Encyclopedia of Cyber-Behavior (pp 671-688). IGI Global; 2012.

[11] Coulson, N.S. How do online patient support communities affect the experience of Inflammatory Bowel Disease? An online survey. J Roy Soc Med 2013; Short Reports, $4(8), 1-8$.

[12] Wilson. E.A.H., Makoul, G., Bojarski, E.A., Bailey, S.C., Waite, K.R., Rapp, D.N., Baker, D.W. \& Wolf, M. Comparative analysis of print and multimedia health materials: A review of the literature. Patient Educ Couns 2012; 89, 7-14.

[13] van de Belt TH, Faber MJ, Knijnenburg, JML, van Duijnhoven NTL, Nelen, WLDM, Kremer JAM. Wikis to facilitate patient participation in developing information leaflets: first experiences, Inform Health Soc Care, 2014, 39(2), 124-139.

[14] Kennedy, I. Patients are experts in their own field. BMJ 2003; 326, 1276-7.

[15] White, M., \& Dorman, S. Receiving social support online: Implications for health education. Health Educ Res 2001; 16(6), 693-707.

[16] King, L.A. \& Miner, K.N. Writing about the perceived benefits of traumatic events: Implications for physical health. Pers Soc Psychol B 2000; 26(2), 220-230.

[17] Langens, T.A., \& Schüler, J. Effects of written emotional expression: The role of positive expectancies. Health Psychol 2007; 26(2), 174-182.

[18] Pennebaker, J.W., \& Beall, S. Confronting a traumatic event: Toward an understanding of inhibition and disease. J Abnorm Psychol 1986; 95(3), 274-281. 
[19] Pennebaker, J.W., Colder, M., \& Sharp, L.K. Accelerating the coping process. J Pers Soc Psychol 1990; 58(3), 528-537.

[20] Stanton, A.L., Danoff-Burg, S., Sworowski, L.A., Collins, C.A., Branstetter, A.D., Rodriguez-Hanley, A., et al. Randomised controlled trial of written emotional expression and benefit finding in breast cancer patients. J Clin Oncol 2002; 20(20), 4160-4168.

[21] Broderick, J.E., Junghaenel, M.A., \& Schwartz, J.E. Written emotional expression produces health benefits in fibromyalgia patients. Psychosom Med 2005; 67(2), 326334.

[22] Archambault, P.M., van de belt, T.H., Grajales III, F.J., Faber, M.J., Kuziemsky, C.E., Gagnon, S. et al., Wikis and collaborative writing applications in health care: A scoping review. J Med Int Res 2013; 15(10): e210.

[23] http://en.wikipedia.org/wiki/Complex regional pain syndrome, last accessed $29^{\text {th }}$ August 2014

[24] http://www.gponline.com/complex-regional-pain-syndrome/pain/symptommanagement/article/1186478 last accessed 29th August 2014

[25] Danis, C. \& Singer, D. A wiki instance in the enterprise: opportunities, concerns and reality. In Proceedings of the ACM 2008 conference on Computer supported cooperative work (pp. 495-504) ACM Press; 2008.

[26] Wagner, C. WIKI: A Technology For Conversational Knowledge Management and Group Collaboration. Communications of the Association for Information Systems 2004; 13, 265-289. 
[27] Kriplean, T.; Beschastnikh, I.; McDonald, D.W. \& Golder, S.A. Community, Consensus, Coercion, Control: CS*W or How Policy Mediates Mass Participation. In Proceedings of ACM GROUP'07 (pp. 167-176) ACM Press, 2007.

[28] Braun V, Clark, V. Successful Qualitative Research: A practical guide for beginners. 2013 London: Sage.

[29] Goebel, A., Barker, C.H., Turner-Stokes, L., et al. (2012). Complex regional pain syndrome in adults: UK guidelines for diagnosis, referral and management in primary and secondary care. London: RCP

[30] Suite of leaflets available from:

https://sites.google.com/site/profkarenrodham/crps/crps-downloadable-docs 
This research was set up because people with CRPS were fed up with the lack of understanding and knowledge about CRPS. People with CRPS said that they wanted to have a space where they could tell others what it was really like to live with CRPS so that other people could understand better. These other people might include friends, family, healthcare professionals, colleagues, employers, benefits agencies and so on.

You may be aware that Wikipedia already has a page on CRPS, but this has in the main been written from the medical profession's perspective. The voice of the people who experience and live with CRPS is not there.

We are now looking for help to write and develop a similar page that will explain and describe CRPS from your point of view. The plan is open the page up to your friends and family in early 2013. They can tell us how useful it is, and whether we need to change anything, before we make the page go live on the Internet in the middle of 2013.

The first task will be to decide on the topics you want to see covered on this new page. So please reply to this post to discuss this amongst yourselves. In a fortnight's time, we will try to collate your ideas so we can begin to work together on writing the content.

Box 1: Invitation to create the wiki page 


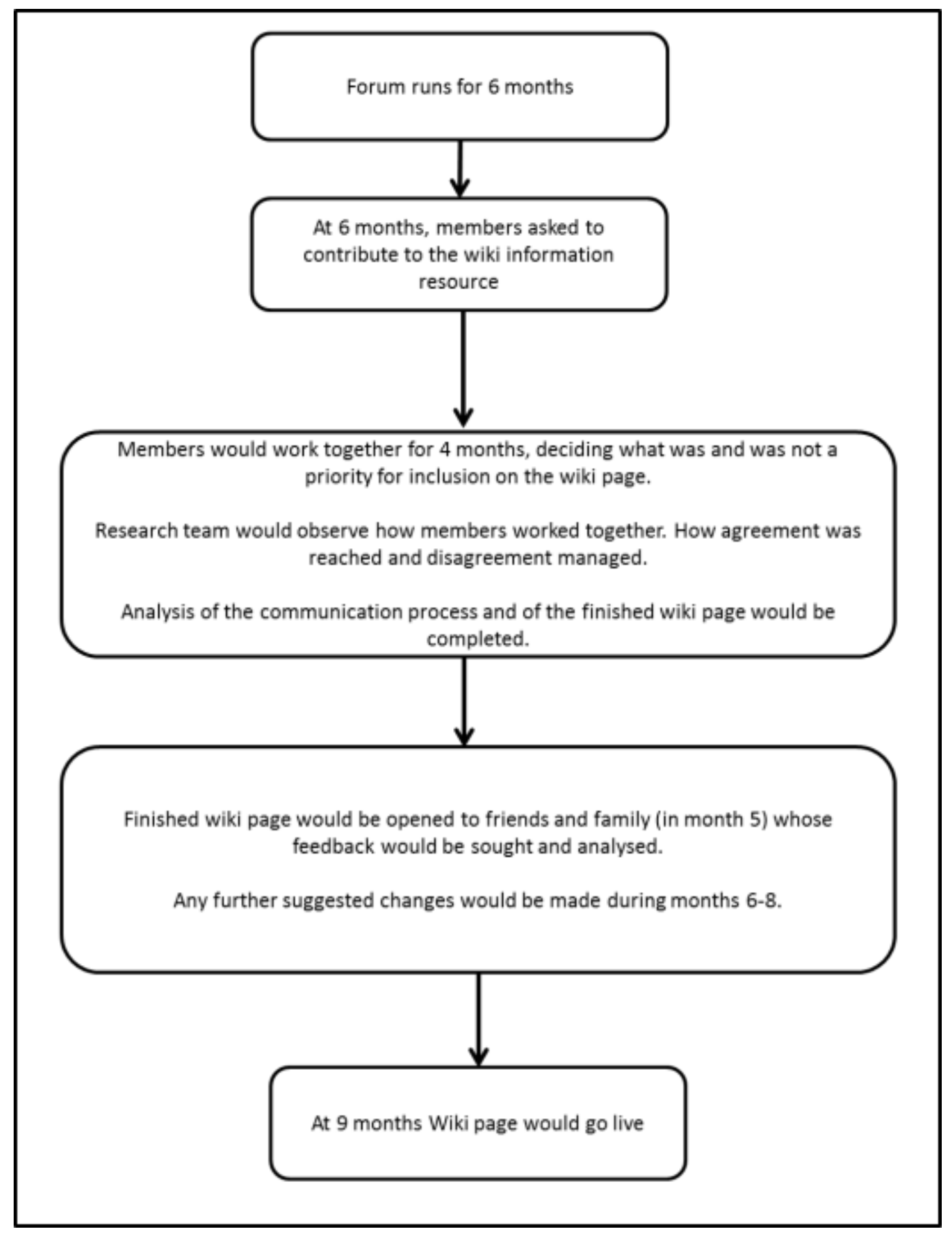

Figure 1 Planned procedure 


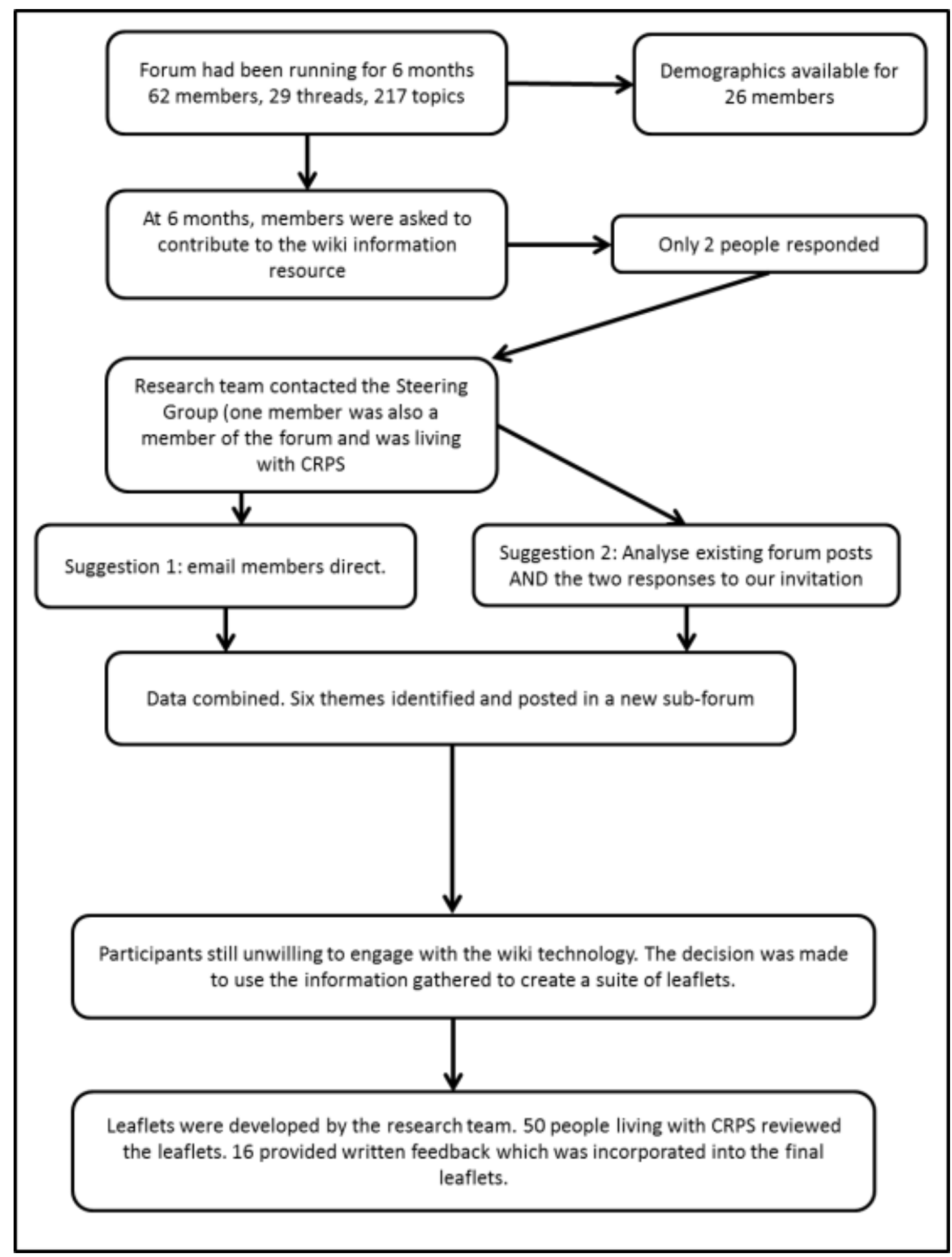

Figure 2 Amended procedure 


\begin{tabular}{|c|c|}
\hline Issue & Comments \\
\hline $\begin{array}{l}\text { Leaflets as a } \\
\text { whole }\end{array}$ & $\begin{array}{l}\text { "These leaflets will be a great asset and take away that jumble of } \\
\text { explanation you find yourself in so often" } \\
\text { "Thank you for representing us and for the above leaflets" } \\
\text { "Brilliant leaflets - am sure they will raise awareness and understanding. } \\
\text { Thank you" } \\
\text { "All the leaflets are a good form of information for everyone from health } \\
\text { professionals to employers. Mainly employers - they have no idea what } \\
\text { CRPS is at all and are too keen to dismiss or discriminate the employee" }\end{array}$ \\
\hline $\begin{array}{l}\text { Health } \\
\text { Professionals } \\
\text { Leaflet }\end{array}$ & $\begin{array}{l}\text { "Love the mantra 'move it, love it, touch it' - perhaps include it in the } \\
\text { other leaflets too" } \\
\text { "Under resources, put the website for CRPS professionals so that they can } \\
\text { network and find out how to get advice" } \\
\text { "I think you should give more options to referral than Bath i.e. Liverpool } \\
\text { (is there anywhere else?) }\end{array}$ \\
\hline Friends & "Could you put the CRPS mantra section that is in the health \\
\hline
\end{tabular}




\begin{tabular}{|c|c|}
\hline Leaflet & $\begin{array}{l}\text { professional's leaflet in the friends and family leaflet, even if it is just the } \\
\text { bit about touching the affected area?" } \\
\text { "Not sure about the picture, but does show pain! Good information about } \\
\text { CRPS showing CRPS is real! To believe the sufferers that they are } \\
\text { experiencing real pain sensitivity etc" }\end{array}$ \\
\hline $\begin{array}{l}\text { Employers } \\
\text { Leaflet }\end{array}$ & $\begin{array}{l}\text { "Extreme hot or cold can affect CRPS so don't sit them near draughty } \\
\text { doors. Allow } 5 \text { mins earlier for breaks to avoid the rush of staff/busyness } \\
\text { in corridors. Allow them to use wheat bags, tens" } \\
\text { "Really good. Employers perhaps need to make allowances if an } \\
\text { employee has to take time off due to pain, but could suggest flexi-time? } \\
\text { Work from home should always be an option if the work is suitable. At } \\
\text { the same time, employees should be accountable and work to the best of } \\
\text { their ability" }\end{array}$ \\
\hline
\end{tabular}

Table 1: Participant comments on the draft leaflets 